\title{
A JURISPRUDÊNCIA BRASILEIRA ACERCA DA MATERNIDADE NA PRISÃO*
}

\author{
Luciana Simas, Miriam Ventura, Michelly Ribeiro Baptista e Bernard Larouzé
}

THE BRAZILIAN JURISPRUDENCE ABOUT MOTHERHOOD

IN PRISON

\section{RESUMO}

O ESTUDO ANALISA CRITICAMENTE DECISÕES QUE ENVOLVEM MULHERES PRESAS E SEUS FILHOS NASCIDOS NA PRISĀO. A PESQUISA FOI REALIZADA NOS BANCOS DE DADOS DO STF, DO STJ E dOS TRIBUNAIS DE JUSTIÇA DO RIO Grande do Sul, Paraná, São Paulo e Mato Grosso, DE 2002 A 2012. DAS 3.720 EMENTAS IDENTIFICADAS A PARTIR DE DESCRITORES ESPECÍFICOS, FORAM SELECIONADOS APENAS 122 DOCUMENTOS RELATIVOS AO OBJETO DA PESQUISA. TAL RESULTADO SUGERE UMA INVISIBILIDADE DO TEMA NA INSTÂNCIA JUDICIAL NO PERÍODO PESQUISADO. GRANDE PARTE DOS JULGADOS REFERE-SE A TRÁFICO, ABORDANDO O CARÁTER HEDIONDO ASSOCIADO AO DELITO E A APLICAÇÃO DE MEDIDAS DE ENCARCERAMENTO, APESAR DE A MAIORIA DAS PRESAS SER PRIMÁRIA E PROVISÓRIA. DESTACAM-SE PEDIDOS DE PRISÃO DOMICILIAR E DE LIBERDADE PROVISÓRIA, EM SUA MAIORIA INDEFERIDOS. O DIREITO INDISPONIVELL DA CRIANÇA À AMAMENTAÇÃO, À SAÚDE E À CONVIVÊNCIA COM A MĀE, POR VEZES, É LIMITADO DIANTE DO DISCURSO DE GARANTIA DA ORDEM E SEGURANÇA PÚBLICA.

PALAVRAS-CHAVE

JUDICIÁRIO; MULHERES; PRISĀO; CRIANÇAS; MATERNIDADE.

\begin{abstract}
THIS ARTICLE PRESENTS A CRITICAL ANALYSIS OF DECISIONS THAT INVOLVES INCARCERATED WOMEN AND THEIR CHILD BORN IN PRISON. A SEARCH WAS PERFORMED IN THE DATA BANKS OF BRAZILIAN SUPERIOR COURTS (THE STF, STJ and the TRIBUnaIS de JUStiça of RIO GRANDE dO SUL, Paraná, São Paulo e Mato Grossol, from 2002 to 2012. FROM THE 3.720 SYLLABUS IDENTIFIED FROM SPECIFIC DESCRIPTORS, ONLY 122 DOCUMENTS RELATING TO THE OBJECT OF RESEARCH WERE CHOSEN. THIS RESULT SUGGESTS THE INVISIBILITY OF THIS THEME IN THE JUDICIAL PROCEEDINGS DURING THE PERIOD SURVEYED. A LARGE PROPORTION OF REASONS ADDUCED REFERS TO DRUGS TRAFFIC, AND ADDRESS THE HIDEOUS NATURE OF THE OFFENCE AND THE APPLICATION OF INCARCERATION MEASURES IN SPITE OF MOST INCARCERATED WOMEN BE PRIMARY AND PROVISIONAL DETAINEES. IT CAN BE HIGHLIGHTED REQUESTS OF DOMICILIARY PRISON AND RELEASE ON BAIL, WHICH, IN MOST INSTANCES, WERE NOT GRANTED. THE CHILD INDISPOSABLE RIGHT TO BREASTFEEDING, TO HEALTH AND TO LIVING WITH HIS MOTHER IS OFTEN LIMITED IN FRONT OF A DISCOURSE OF GUARANTEE OF ORDER AND PUBLIC SECURITY.
\end{abstract}

\section{KEYWORDS}

JUDICIARY; WOMEN; PRISON; CHILDREN; MATERNITY. 
"É impossível passar por uma prisão e sair sem marcas e feridas. Acontece com todos. Com os que pra lá são mandados, para cumprir uma pena. Com funcionários e visitantes. E, por que não, com pesquisadores.” (Lemgruber, 1999, p. 13)

Complementa Armelin (2010, p. 6): “qualquer pessoa que tem contato com uma prisão sofrerá alguma mudança, e assim, devemos incluir os filhos das mulheres encarceradas".

\section{INTRODUÇÃO}

De acordo com dados oficiais do Ministério da Justiça (DEPEN, 2011), em dezembro de 2011, existiam 34.058 mulheres encarceradas, o que representa cerca de $7 \%$ do total da população penitenciária, em uma vertiginosa ascensão (aumento de $98,7 \%$ de 2005 a 2011). Também se observa o crescimento acentuado da aplicação do regime fechado e de prisões provisórias. A distribuição dessa população por regimes de cumprimento de pena era: 44,1\% da população feminina (12.945 mulheres) cumpria pena em regime fechado, 15,7\% (4.607 mulheres) em regime semiaberto, 4,1\% (1.201 mulheres) em regime aberto e 34,4\% (10.100 mulheres) em regime provisório, no sistema de polícia. Havia ainda o contingente de 1,7\% da população feminina (494 mulheres) em cumprimento de medida de segurança. Portanto, 78,5\% do total encontrava-se em unidades prisionais, como penitenciárias ou delegacias.

A prisão feminina expõe especificidades correlacionadas ao gênero - como questões de saúde reprodutiva e infantil, de proteção e assistência social à maternidade e à infância nesse ambiente - que refletem, no contexto ético-jurídico contemporâneo, direitos humanos reconhecidos no âmbito internacional e nacional.

No cenário brasileiro, a Constituição Federal garante direitos fundamentais à população feminina carcerária, como o de amamentar seus filhos e ter sua integridade física e moral respeitada (art. $5^{\circ}$, incisos L, XLIX). ${ }^{1}$ Inclui expressamente o dever de proteção à maternidade (art. $6^{\circ}$, caput) e a assistência gratuita à criança até seis anos de idade em creches e pré-escolas (art. $7^{\circ}$, inciso XXV), como direitos sociais. A proteção da maternidade é reiterada como um direito previdenciário e de assistência social (art. 201, inciso III, e art. 203, inciso I), assegurando-se, ainda, amplo direito à saúde, com acesso universal igualitário às ações e aos serviços de saúde (art. 196). Como direitos de família, garante a livre decisão da pessoa sobre o número, o espaçamento e a oportunidade de ter filhos (art. 226, § $7^{\circ}$ ), livre de coerções e discriminações de qualquer espécie (VENTURA, 2009). E à criança são resguardados, com absoluta prioridade, os direitos à vida, à saúde, ao respeito, à liberdade, à convivência familiar e comunitária, a salvo de qualquer negligência, violência, crueldade ou opressão (art. 227, CF). 
As alterações legislativas sofridas pela Lei de Execução Penal (LEP) (Lei n. 7.210/84) e pelo Código de Processo Penal (CPP) (Decreto-Lei n. 3.689/41), respectivamente nos anos de 2009 e $2011^{2}$, representam avanços normativos a respeito do tema (VENTURA et al., 2015). Preveem acompanhamento médico à mulher e ao recém-nascido; obrigatoriedade de berçário com tempo mínimo de amamentação de seis meses; seção para gestante e parturiente, com creche para filhos desamparados maiores de seis meses e menores de sete anos; regime aberto domiciliar para condenada gestante ou com filho menor ou, ainda, deficiente físico ou mental; bem como prisão domiciliar como medida cautelar. No mesmo sentido, o Estatuto da Criança e do Adolescente (ECA) (Lei n. 8.069/90), modificado pela Lei n. 12.962/14, determina a impossibilidade da perda do poder familiar pela condenação criminal, exceto no caso de condenação por crime doloso sujeito à reclusão contra o próprio filho, garantindo o direito à convivência familiar, à assistência social.

Além da legislação interna favorável, o Brasil é signatário dos Tratados Internacionais de Direitos Humanos. Participa ativamente da implementação dos planos resultantes da Conferência Internacional da ONU sobre População e Desenvolvimento (CIPD) (CAIRO, 1994), que tratou das questões de direitos e saúde reprodutiva e das famílias, incluindo a população carcerária (BRASIL, 2005), bem como das Regras de Bangkok, das Nações Unidas, para o tratamento de mulheres presas e medidas não privativas de liberdade para mulheres infratoras (ONU, 2010).

A maioria das mulheres é acusada de praticar crimes sem violência e, no mais das vezes, por envolvimento com drogas. Os dados do DEPEN (2011) convergem com essa análise apontando que as presas condenadas por tráfico (nacional e internacional) representam $64 \%$ da população feminina nas penitenciárias brasileiras. O perfil social das mulheres privadas de liberdade revela, em sua larga maioria, origem em classes populares, baixa instrução e exclusão do mercado formal de trabalho. Nesse sentido, o processo de criminalização da miséria abordado por Löic Wacquant (2003) é transportado por Santos para a realidade brasileira, quando percebe que:

a prisão funciona como principal aparelho punitivo e de repressão sobre essa classe, e o Estado enquanto principal regulador dessa política máxima quanto à salvaguarda dos interesses capitalistas e mínima quando se refere à responsabilização frente aos investimentos sociais. O sistema penitenciário brasileiro não foge a essa regra e seus indicadores vêm demonstrando a ineficácia dos argumentos de reintegração social contraditoriamente ao seu papel segregador e vulnerabilizador de determinados segmentos da sociedade. (SANTOS, 2011, p. 45)

Posto em xeque o discurso de ressocialização e a retórica da garantia de direitos dos presos, é possível ratificar que o cárcere concretiza uma dupla discriminação (por 
ser mulher e presa) e tem se mantido fiel ao seu papel ao longo da história: "punir e castigar através do afastamento social” (SANTOS, 2011, p. 45).

Além disso, conforme observam Rodolfo Valente, Heidi Ann Cerneka e Fernanda Baler (2011), a falta de políticas públicas que considerem a prisão sob a perspectiva de gênero acaba por gerar uma verdadeira "sobrepena" para as mulheres. Constata-se uma "inadequação estrutural do sistema prisional às necessidades femininas”, pois, em regra, as prisões femininas seriam adaptações das masculinas, o que torna os impactos da prisão ainda mais severos, implicando uma sistemática violação dos direitos humanos.

Ao discutir a separação entre mãe e filho em função do cárcere, Claudia Stella (2009) reflete sobre questões como a culpabilização sobre o abandono sofrido, abalos na estrutura familiar e a possibilidade do filho desamparado "retroalimentar a carreira do crime". O estigma social enfrentado, o papel social da mãe no ambiente familiar, os estereótipos aceitos tradicionalmente sobre masculino e feminino, bem como o próprio conceito de família, são temas a serem considerados quando se discute maternidade no contexto prisional, considerando-se que, "quando o pai é preso, a maioria das crianças continua sendo cuidada pela mãe. Contudo, quando da prisão materna, somente $10 \%$ das crianças continuam sendo cuidadas pelos companheiros das mães" (GABEL apud STELLA, 2009).

Conforme descrito por Armelin (2010), as crianças que iniciam a vida no alojamento conjunto de uma prisão, sendo privadas de conviver na sociedade livre, encontram-se em uma situação peculiar, dentro de uma instituição total. Nesse sentido, "a privação pela qual a criança passa deixa evidente a discrepância no desenvolvimento entre uma criança 'livre' e uma criança que vive atrás dos muros de uma penitenciária”, que acaba não conseguindo ter uma convivência normal com sua genitora. Segundo a autora (2010, p. 12), o ambiente impróprio, que não oferece meios adequados de locomoção nem objetos que possam ser usados em atividades espontâneas, acaba por aprisionar mais as crianças que as próprias mães, tendo em vista que a falta de condições ambientais interfere de maneira negativa no desenvolvimento do filho. Porém, a criança é percebida pelas presas como uma motivação para que a mulher consiga cumprir a pena de uma maneira mais tranquila, modificando seus comportamentos; por isso, impedir o convívio seria mais uma das várias privações que a detenção ocasiona (ARMELIN, 2010, p. 13).

A abordagem desse tema complexo exige uma análise das respostas emanadas pelo Poder Judiciário na garantia dos direitos dessa parcela vulnerável da população. Para tanto, a pesquisa jurisprudencial surge como caminho adequado para se compreender o "dizer do direito" em relação ao assunto e evidencia o grau de eficácia das normas ao concretizar sua aplicação. Considerando-se que a jurisprudência representa o posicionamento de determinado órgão do Poder Judiciário, identifica-se, desse modo, a palavra final acerca do conflito. 
Notadamente no campo criminal, a prisão simboliza um "aspirador da escória social”, refugo da sociedade de mercado (WACQUANT, 2003, 2004), representando a junção de violências e humilhações cotidianas, como vetor de desagregação familiar, de desconfiança cívica e de alienação individual. Correlacionando-se com o objeto de estudo deste artigo, é importante perceber que:

o impacto danoso do encarceramento não age apenas sobre o detento, mas também, e de modo mais insidioso e injusto, sobre sua família: deterioração da situação financeira, desagregação das relações de amizade e de vizinhança, enfraquecimento dos vínculos afetivos, distúrbios na escolaridade dos filhos e perturbações psicológicas graves decorrentes do sentimento de exclusão aumentam o fardo penal. (WACQUANT, 2004, p. 221)

A vulnerabilidade das mulheres encarceradas é ainda mais acentuada para as detentas grávidas e para aquelas que, tendo dado à luz seus filhos durante o encarceramento, vivem com eles em prisões insalubres, sob a vigilância constante e num contexto incompatível com um desenvolvimento afetivo, motor e psicossocial harmonioso. Levantamento seccional realizado em 2012, no âmbito macro desta pesquisa junto às administrações penitenciárias dos estados brasileiros (LEAL et al., 2014), mostrou que $2 \%$ das 23.782 mulheres encarceradas encontravam-se grávidas e, no período de um ano, 272 presas tiveram seus filhos no cárcere. Cerca de 400 crianças (das quais 370 com menos de 1 ano) viviam com suas mães em prisões, o que justificou o levantamento objeto deste artigo. Todavia, não foram identificados estudos jurisprudenciais sobre essa população precarizada e negligenciada na busca bibliográfica empreendida no período pesquisado, tornando-se relevante este estudo, cujo objetivo é compreender como a questão da maternidade das mulheres presas e da vida de seus filhos nascidos na prisão tem sido tratada pelos magistrados nacionais. Para tanto, realizamos análise do conteúdo de decisões dos Tribunais Superiores e Tribunais de Justiça locais.

O presente artigo é fruto dessa pesquisa multidisciplinar realizada no âmbito do macroprojeto Saúde Materno-Infantil nas Prisões do Brasil, desenvolvido pela Escola Nacional de Saúde Pública (ENSP)/Fiocruz, com abrangência nacional. Além do componente jurídico, foram realizados estudos relacionados à atenção à saúde da mulher e da criança, bem como aos aspectos psicossociais e arquitetônicos das condições prisionais. A análise do debate jurídico foi organizada em duas partes. Na primeira, apresentaremos aspectos metodológicos do estudo. Na segunda, discutiremos os resultados obtidos. Almejamos pontuar durante a discussão as questões mais relevantes dos julgados e retomaremos os aspectos emblemáticos nas considerações finais. 


\section{Metodologia}

Trata-se de estudo seccional retrospectivo de decisões do Poder Judiciário concernentes aos direitos das presas e de seus filhos nascidos no sistema penitenciário. Buscou-se entrelaçar conhecimentos do Direito, das Ciências Sociais, da Saúde Pública e da Criminologia, no intuito de sistematizar, de maneira original, as posições oficiais dos magistrados de segunda instância e de Tribunais Superiores sobre o assunto.

A dimensão empírica da pesquisa jurisprudencial permitiu observar como os direitos das mulheres e de seus filhos nos presídios brasileiros - no tocante à saúde, à proteção à maternidade, à família e ao apoio social - vêm sendo abordados no âmbito nacional pelo Supremo Tribunal Federal (STF) e pelo Superior Tribunal de Justiça (STJ). A busca e análise das jurisprudências locais foi realizada nos meses de novembro de 2012 a abril de 2013 e permitiu uma abordagem comparativa, nos Tribunais de Justiça (TJs) de Rio Grande do Sul, Paraná, São Paulo e Mato Grosso. A escolha desses Tribunais Locais ocorreu a partir de uma amostra de conveniência e considerou o grande contingente de mulheres com filhos na prisão nesses estados, identificado na pesquisa mais ampla, bem como o tempo disponível para análise no âmbito do macroprojeto.

A busca e a sistematização da jurisprudência federal e estadual geraram um banco de dados capaz de consolidar as decisões relativas à maternidade, ao nascimento e ao desenvolvimento da criança no ambiente carcerário. Para tanto, foram adotados em todos os tribunais os mesmos descritores: presa e filho; amamentação e presa; creche e presa; poder familiar e presa; prisão domiciliar e mãe e/ou filho(a); saúde materna infantil e prisão; adoção e presa e criança; pátrio poder e presa; presidiária e filho(a); maternidade e presa; Lei n. 12.403/11 presa e filho(a) e maternidade; saúde materna infantil e presa; maternidade e prisão domiciliar.

As fontes de dados secundárias utilizadas foram as bases de dados dos referidos tribunais. Quanto aos critérios de inclusão, compuseram o universo do estudo as decisões judiciais proferidas durante o período de 01/01/2002 a 10/11/2012 que contivessem na ementa algum dos descritores eleitos. Foram excluídos acórdãos que não abordassem questões ligadas ao exercício da maternidade pelas presas ou direitos de seus filhos. Como o levantamento dos dados começou em novembro de 2012, buscou-se abranger os dez anos anteriores de produção decisória.

A coleta de informações jurisprudenciais foi iniciada pela base de dados institucional do STF, tendo sido privilegiada a pesquisa livre, para se evitar a seleção prévia de conteúdos pela administração, como ocorre na modalidade de pesquisa de jurisprudência selecionada por assunto. Destarte, optou-se metodologicamente por um levantamento sem filtro, abrangendo acórdãos, súmulas, súmulas vinculantes e decisões monocráticas, por serem variáveis jurisprudenciais relevantes.

Procedimento metodológico similar foi adotado na pesquisa na base de dados do STJ. Conquanto sejam disponibilizadas decisões previamente selecionadas sobre 
temas jurídicos, bem como acórdãos com julgamentos de casos notórios ou por ramo específico do direito, igualmente foi adotada a busca livre com o uso de operadores específicos.

Do mesmo modo foram realizadas as buscas nos sites oficiais dos Tribunais de Justiça. Embora possuam competências semelhantes, os Tribunais Locais dispõem de bancos de dados muito diversos, o que, de certa forma, dificulta a análise comparativa. Apesar de grandes investimentos do Poder Judiciário na ampliação de mecanismos de informatização, facilitando a publicidade da tramitação processual e a realização de pesquisas a partir de diversos ângulos, a organização dos sites oficiais dos Tribunais de Justiça permanece muito heterogênea, limitando o acesso às decisões judiciais.

Considerando as especificidades de cada banco de dados estadual, foram utilizadas buscas avançadas, mais completas, no intuito de permitir a pesquisa por descritores e por período determinado, relativo tanto à data de julgamento, quanto à da publicação da decisão. Foram selecionados acórdãos e decisões monocráticas, nas áreas criminal e cível, para que se pudesse ampliar os campos de busca e obter uma real dimensão da atuação do órgão acerca dos direitos das mães presas e seus filhos. Destarte, manteve-se a compatibilidade com os demais bancos de dados e um padrão de busca.

\section{Resultados e Discussão}

De todos os tribunais pesquisados, foram identificadas 3.721 decisões que continham em suas ementas algum dos descritores elencados acima. A partir de uma leitura inicial dessas ementas, foram selecionados somente os documentos que diziam respeito especificamente ao objeto da pesquisa relatada, resultando em 177 decisões. Uma segunda etapa de exclusões ocorreu a partir da leitura dessas decisões na íntegra, sistematizando os achados de acordo com a incidência dos descritores, permitindo a identificação de repetições. O resultado dessa etapa totalizou 122 documentos para análise crítica, conforme distribuição a seguir.

QUADRO 1 - DisTRIBUIÇÃO DAS DECISÕES JUDICIAIS INCLUÍDAS NA ANÁLISE, SEGUNDO O TRIBUNAL E DESCRITORES

\begin{tabular}{lccccccc}
\hline 1. SAÚDE MATERNA INFANTIL E PRISÃO & 0 & 0 & 0 & 0 & 0 & 1 & 1 \\
\hline 2. PRESA E FILHO(A) & 8 & 3 & 24 & 7 & 1 & 14 & 57 \\
\hline 3. ADOÇÃO E PRESA E CRIANC̦A & 0 & 0 & 1 & 1 & 0 & 2 & 4 \\
\hline
\end{tabular}


A JURISPRUdÊNCIA BRASILEIRA ACERCA DA MATERNIDADE NA PRISÃo

\begin{tabular}{|c|c|c|c|c|c|c|c|}
\hline 4. AMAMENTAÇÃO E PRESA & 1 & 2 & 0 & 2 & 17 & 15 & 37 \\
\hline 5. CRECHE E PRESA & 0 & 0 & 0 & 0 & 0 & 5 & 5 \\
\hline 6. PODER FAMILIAR E PRESA & 0 & 0 & 8 & 0 & 3 & 4 & 15 \\
\hline 7. PÁTRIO PODER E PRESA & 0 & 0 & 2 & 0 & 0 & 1 & 3 \\
\hline 8. PRISÃO DOMICILIAR E MÃE E FILHO(A) & 3 & 3 & 4 & 2 & 2 & 14 & 28 \\
\hline 9. PRESIDIÁRIA E FILHO & 0 & 0 & 8 & 0 & 0 & 5 & 13 \\
\hline 10. MATERNIDADE E PRESA & 1 & 0 & 0 & 0 & 0 & 3 & 4 \\
\hline 11. LEI N. 12.403/11 E PRESA E FILHO(A) E MATERNIDADE & 0 & 0 & 1 & 1 & 1 & 0 & 3 \\
\hline 12. SAÚDE MATERNA INFANTIL E PRESA & 0 & 0 & 0 & 0 & 1 & 0 & 1 \\
\hline 13. MATERNIDADE E PRISÃO DOMICILIAR & 1 & 0 & 2 & 0 & 3 & 0 & 6 \\
\hline SUBTOTAL & 14 & 8 & 50 & 13 & 28 & 64 & 177 \\
\hline TOTAL SEM REPETIC̣ÕES & 12 & 5 & 32 & 10 & 25 & 38 & 122 \\
\hline
\end{tabular}

Fontes: STF, STJ, TJRS, TJSP, TJPR, TJMT. Elaboração própria.

Observa-se que o descritor que apresentou menor incidência foi "saúde materna infantil e prisão", contrapondo-se aos termos "presa e filho(a)", mais utilizados pelo Judiciário. Também foi constatada uma abordagem considerável em relação à amamentação e à prisão domiciliar.

Para a análise de todas as 122 decisões, foi organizado um banco de dados com as principais variáveis de interesse, como: número do processo; data da publicação da decisão; tipo da decisão (monocrática ou colegiada); procedimento judicial (por exemplo, se Agravo de Instrumento, Habeas Corpus, Apelação etc.); partes; relator; órgão julgador; juízo de origem; ementa; crime denunciado; pena aplicada; natureza de prisão; pedido de benefício (prisão domiciliar, livramento condicional, progressão de regime, liberdade provisória e outros); outros pedidos; representação processual; motivação para o pedido (por exemplo, não há estabelecimento adequado ao regime/ está em estabelecimento masculino/ gravidez de risco/ grávida/ filho deficiente/ menor/ outros); decisão (provido/ desprovido/ parcialmente provido); base legal; destinação da criança; se houve consulta prévia a algum órgão para a decisão (por exemplo, Conselho Tutelar, Ministério Público, Vara da Infância, órgãos da saúde); observações gerais. 


\section{I Decisões dos Tribunais Superiores}

Constatamos inicialmente que o tema das crianças que permanecem com sua mãe na prisão ainda não foi recorrente nos Tribunais Superiores. A incipiente produção jurisprudencial durante o período analisado (2002-2012) nos órgãos de cúpula do Judiciário comprova a "invisibilidade da questão", que poderia ser explicada pelo menor percentual de mulheres no universo prisional, pelo preconceito referente à garantia dos direitos das presas ou por dificuldades de efetivo acesso à Justiça, que envolvem motivações e acessibilidade das próprias presas à Defensoria Pública, aos advogados e ao Ministério Público.

O STF proferiu, durante dez anos, somente doze decisões que discutiram filho(a), amamentação, prisão domiciliar e maternidade, todas correlacionadas à situação da presa. As decisões foram monocráticas, emanadas do próprio relator, ou seja, a questão nem sequer chegou a ser debatida pelo plenário das Turmas do STF. No único caso no qual o acórdão foi proferido a partir da discussão por um órgão colegiado, foi concedido o pedido de liberdade provisória para uma presa sob os argumentos de que estava muito doente e sua filha menor lhe era dependente economicamente. $\mathrm{O}$ relato do caso informava que a mulher encontrava-se privada de liberdade cautelarmente havia cinco anos por crime hediondo e conseguiu o benefício da liberdade provisória, sendo que o Ministério Público recorreu, cassando o benefício. A acusada, porém, não foi encontrada para cumprimento do mandado de prisão por um erro cadastral no sistema judiciário. Nesse ínterim, ela foi infectada pelo vírus HIV, contraindo também hepatite C e HTLV (HC 94916, public. 12/12/2008). A controvérsia jurídico-processual dizia respeito à possibilidade de liberdade provisória em denúncias por tráfico de entorpecentes. A decisão considerou irrelevante esse aspecto, principalmente diante da ausência de justificativa para prisão cautelar.

A fundamentação do voto do relator, Ministro Eros Grau, expõe que a prisão, na hipótese de condenação por tráfico de drogas, baseia-se verdadeiramente na "vingança”. Assim discorre: “A submissão da paciente ao cárcere é incompatível com o direito, ainda que se possa ter como adequado à regra. Manter presa em condições intoleráveis uma pessoa doente não restabelece a ordem, além de nada reparar. Situação peculiar a configurar exceção”, permitida pelo ordenamento jurídico (HC 94916).

A decisão foi embasada no princípio da dignidade da pessoa humana, e, analisandose o voto proferido pelo relator, observamos o perfil clássico da maioria das mulheres presas: primária, de bons antecedentes, com emprego e residência fixos, flagrada com pequena quantidade de droga (maconha) quando visitava o marido na penitenciária.

Outro pedido de liberdade provisória de uma presa cautelar teve desfecho completamente diferente, tendo sido indeferido de plano pelo Ministro Relator Luiz Fux (HC 109960/DF, public. 29/08/2011). A presa alegava sofrer constrangimento ilegal, pois, após dar à luz, em vez de ser transferida junto com o recém-nascido para 
uma unidade prisional com suporte à maternidade, o bebê foi entregue, após três dias de nascido, aos cuidados da avó materna. A mãe foi encaminhada para o estabelecimento prisional da comarca de Águas da Prata (SP), situada a mais de cem quilômetros do local onde se encontrava a criança, ficando, por esse motivo, o recém-nascido privado de receber o aleitamento materno. Informou que, dias depois, foi novamente transferida para a Penitenciária Feminina do Carandiru, onde permaneceu por mais de um mês com o filho. A presa requereu liberdade provisória e prisão domiciliar; contudo, foram indeferidas, com base em dois argumentos: 1) já havia outro habeas corpus anterior com o objeto idêntico (liberdade provisória) ainda não julgado, portanto seria mera reiteração; 2) quanto ao pedido de prisão domiciliar, não poderia ser apreciado antes da manifestação das instâncias judiciais inferiores. Ou seja, são dois argumentos processuais utilizados sem atacar o mérito da questão.

Procuramos especificamente o habeas corpus "original" mencionado na decisão acima (HC 108757, julgado a posteriori, em 21/03/2012) e foi constatado que nessa decisão não foi feita nenhuma menção específica à maternidade. O pedido de liberdade provisória foi apenas declarado prejudicado por perda do objeto - ou seja, também não foi apreciado materialmente - diante da condenação definitiva da presa a oito anos de reclusão.

Nesse sentido, oito dos processos identificados no âmbito do STF (66,6\% do total) foram negados - cinco deles diretamente pelo Ministro Luiz Fux -, e um restou prejudicado pela absolvição da presa. Todos os pedidos diziam respeito a benefícios no processo penal, e a maioria era de prisão domiciliar (total de seis pedidos principais, que equivaleu a 50\% do universo pesquisado); outras três solicitações de liberdade provisória; um pedido de fixação do regime inicial aberto com substituição da pena privativa de liberdade; um de revogação de prisão cautelar; e um de saída para estudo. Este último também foi negado, fazendo-se referência a um benefício de prisão domiciliar concedido anteriormente para que a presa cuidasse do filho com doença psiquiátrica. Para esse entendimento, o fato de estar sujeita à prisão domiciliar para cuidar do filho impediria a presa de sair para estudo, mesmo tendo passado no vestibular (HC 112385 , Relatora Min. Rosa Weber, decisão monocrática em 12/03/2012).

A situação também não é muito diferente no STJ, onde foram proferidas apenas cinco decisões sobre o tema pesquisado, nos dez anos analisados. Todas foram emanadas de órgãos colegiados criminais e diziam respeito a pedidos de prisão domiciliar, sendo três negados e dois aceitos.

Em um dos casos julgados procedentes, há uma verdadeira "pérola de atrocidade", proferida pelo magistrado de primeira instância (HC 115.941/PE, public. 03/08/2009). A presa descrevia uma situação de constrangimento ilegal, pois estava reclusa em estabelecimento carcerário destinado ao sexo masculino, impossibilitada de amamentar o filho recém-nascido. Essa circunstância a impediria de prestar o devido auxílio ao lactente, cujo estado de saúde viria se agravando em razão da alimentação imprópria 
que lhe era ministrada. Buscava, então, a conversão da prisão provisória em prisão domiciliar, negada pelo juiz de primeiro grau, segundo o qual:

No entendimento deste juízo, quem cometer um delito na Inglaterra, em princípio, condenado deve cumprir a pena na Inglaterra. Quem praticar delito em Pernambuco fica sujeito ao Sistema Prisional de Pernambuco e toda sua realidade. Esta realidade todo dia é exposta nos jornais, no rádio e televisão. No entendimento deste juiz, não tem cabimento uma pessoa cometer um delito em Pernambuco e pensar que está sujeito ao sistema prisional da Inglaterra. A cadeia pública feminina da cidade de Verdejante, justamente por ser feminina, deve atender na medida da realidade do Sertão Pernambucano, as condições específicas da mulher, tal como a ocorrência de gestação ou de aleitamento materno que podem ocorrer em presas. Esta, no entendimento deste juízo, é uma situação totalmente previsível e esperada em presídios femininos. [...] Segundo o sistema prisional pernambucano real e posto em prática, havendo presa em cadeia feminina a pena não está ainda além da mãe. Diante do exposto, quando este juízo se manifestou anteriormente no sentido de que considerava que o pedido havia perdido o seu objeto, isto quis dizer que a presa já havia sido transferida para um local adequado, destinado a presidiárias.

Essa decisão foi mantida pelo Tribunal de Justiça local, porém o STJ a reformou com os argumentos de que a detenção ocorreria em comarca diversa de onde se encontrava a criança necessitando de amamentação; bem como, diante da fixação do regime inicial semiaberto, seria possível a aplicação analógica do artigo 117 da Lei de Execução Penal (LEP), que disciplina a prisão domiciliar, "em nome da dignidade da pessoa humana ${ }^{3}$ e proporcional no caso concreto”. A Ministra Relatora Maria Thereza de Assis Moura esclareceu que:

Nos termos do artigo $3^{\circ}$ da Lei de Execução Penal, "ao condenado e ao internado serão assegurados todos os direitos não atingidos pela sentença ou lei”. Assim, quanto mais em relação ao preso provisório, deverá ser-lhe assegurado o exercício destes mesmos direitos. No caso, tem a mãe o direito de amamentar e prestar assistência à criança que gerou. Se não há na Comarca de Juazeiro local adequado para que possa estar perto de sua família e amamentar e cuidar do bebê, ainda que estando recolhida em estabelecimento prisional, penso que deve ser-lhe assegurado o direito de permanecer em prisão domiciliar. Ora, trata-se de direito individual fundamental [...] Há, é verdade, o interesse da administração da justiça em que a paciente fique na comarca em que cometido o delito (Trindade/PE), 
como ressaltado pelo juízo de primeiro grau. Todavia, o interesse da administração da justiça também há que ser sopesado em relação ao interesse do menor lactente em ter a assistência da mãe nestes primeiros anos de vida. Por outro lado, com a prolação da sentença, penso que não se verifica mais qualquer razão para que a paciente seja mantida na Comarca em que teria sido cometida a infração criminal. [...] mostrando proporcional e razoável que a paciente fique em regime domiciliar para dar maior assistência a seu filho, especialmente diante da notícia de que a avó da criança, a quem incumbiam os seus cuidados, ficou viúva recentemente.

Dentre os processos julgados improcedentes, podemos observar, exemplificativamente, um caso no qual a ré pedia a prisão domiciliar para cuidar e amamentar o filho menor que é deficiente físico (HC 133287, public. em 03/05/2010). Ela apresentou um laudo médico indicando medidas necessárias à recuperação da criança, como "amamentação contínua para ganhar peso, para possível correção cirúrgica imediata, e cuidados permanentes tipo materno-infantil”. Contudo o relator, Ministro Felix Fischer, apontou um ofício do Centro de Ressocialização Feminino de São José do Rio Preto, o qual informava que à presa vinha sendo assegurado "o direito de amamentar seu filho, em local com higiene adequada, restando cumprido, portanto, o artigo 83, $\S 2^{\circ}$ da lei n. 7.210/84”. O pedido do benefício foi negado, com base em entendimento de não ser possível conceder liberdade provisória nos crimes hediondos e aos a eles equiparados. Assim, a acusação de tráfico ilícito de entorpecentes implicaria a proibição da liberdade provisória, nos termos do artigo 44 da Lei n. 11.343/06, combinado com o artigo $5^{\circ}$, XLIII, da Carta Magna, o qual impede a concessão de fiança. O Tribunal considerou não ser razoável conceder o benefício para a ré apelar em liberdade, uma vez que ficou presa durante toda a instrução criminal e, com relação à garantia de permanência com o filho durante o período de amamentação (art. 5 L, da Constituição da República), "não significa que todas as lactantes tenham direito a cumprir pena em domicílio, mas, ao contrário, pressupõe o recolhimento ao estabelecimento prisional público”.

\subsection{Decisões dos Tribunais de Justiça estaduais}

Partimos, então, para a análise nos Tribunais de Justiça, denominados de segunda instância, no intuito de verificar as semelhanças ou as discrepâncias com os Tribunais Superiores. OTJRS, analisado comparativamente com os demais tribunais estaduais, concentrou a maior quantidade de processos cíveis acerca do tema maternidade na prisão, e todas as decisões foram proferidas por órgãos colegiados. Do total de 32 decisões identificadas, treze não eram processos criminais. Havia nove pedidos de manutenção do poder familiar da mãe que se encontrava presa; todos foram negados. De modo geral, fundamentando-se no "abandono, negligência e ausência ao dever de 
guarda e cuidado com os filhos. Mãe presa em flagrante por envolvimento no crime de tráfico de entorpecentes. Pai viciado em crack” (Apelação Cível 70045900180); "Crianças vítimas de descaso e negligência. Mãe usuária de crack e atualmente presa por tráfico. Situação de extremo risco e vulnerabilidade” (Apelação Cível 70047165287). Havia mais três pedidos de mudança de guarda, também negados às mães. E um recurso do Ministério Público, deferido, para ouvir o consentimento de uma mãe presa que concordava em encaminhar as filhas para a adoção. Associa-se, desse modo, privação de liberdade e uso de drogas com perda do poder familiar.

Nos dezenove processos criminais localizados, encontram-se dez pedidos de prisão domiciliar, oito de liberdade provisória e um de nulidade do PAD (processo administrativo disciplinar) por fuga e regressão do regime de cumprimento da pena. Ao todo, foram doze decisões contrárias à concessão de benefícios e sete favoráveis.

No processo no qual se discutia a fuga da presa, foi narrado que ela ficou recolhida um ano no regime fechado aguardando sua condenação. Nessa época, seu único filho tinha 1 ano e 2 meses e havia ficado aos cuidados do pai, que, embora tivesse prometido levá-lo para visitação, nunca o fez. Sobreveio sua condenação em 6 anos, 2 meses e 20 dias de reclusão em regime semiaberto. Aproximadamente quinze dias após a fixação da pena, a presa ficou sabendo que o filho estava muito doente (infecção pulmonar) e, somando a preocupação à saudade, resolveu fugir da Casa Albergue Feminino (CAF) a fim de poder vê-lo. Segundo relato da mãe privada de liberdade, ela só fugiu porque a saudade e a preocupação maternal foram mais fortes do que a razão. Asseverou ainda que, durante o tempo em que esteve foragida, via o filho sempre que possível, manteve-se trabalhando e reorganizando a vida familiar. Após três meses, conseguiu um emprego. Desejava terminar o cumprimento de sua pena para poder retornar ao convívio dos seus o mais rápido possível (Agravo em Execução 70033645359). Contudo, o pedido de nulidade da regressão do regime prisional foi negado, significando que a mulher, que cumpria pena em regime semiaberto, passou para o regime fechado. A Desembargadora Relatora Fabianne Breton Baisch discorreu que:

As razões expostas pela condenada - de que seu filho ficara doente - não têm o condão de descaracterizar a conduta infracional, enquadrada como falta grave, denotando o desajustamento daquela com o regime que estava a cumprir, revelando a conduta comprometimento sério à execução, frustrando uma das finalidades fundamentais do sistema execucional, identificada como a reinserção social, com o que o Estado, que exerce tal mister, não se pode compadecer.

O segundo tribunal analisado foi o TJPR, que disponibilizou em seu site oficial 25 decisões acerca do objeto da pesquisa, sendo três de natureza civil: uma ação de 
reparação de danos do filho em face do Estado pelo falecimento de sua mãe presa; e dois recursos em ações de destituição do poder familiar. Nestes, as apelantes eram mulheres privadas de liberdade por tráfico de drogas, que tiveram seus recursos negados sob a alegação de abandono das crianças. Em um desses casos, tanto a mãe quanto o pai recorreram, tentando manter o poder familiar, entretanto as duas apelações foram negadas. Assim descreve o acórdão (Apelação Cível 634147-5):

Pai em liberdade condicional - Mãe cumprindo pena em regime fechado Ambos por tráfico de drogas - Infantes residentes com a avó materna Higiene precária - Abrigamento - Rejeição da menor pelo pai - Laudo técnico desfavorável - Manifestação de vontade da infante em permanecer abrigada ou ser inserida em nova família - Ausência de condições materiais e morais para manutenção do poder familiar - Sentença mantida Recurso desprovido.

A mãe alegava que em breve teria cumprido sua pena, podendo, então, reconstituir a vida e arcar com a responsabilidade de bem cuidar dos filhos, e, até que se encerrasse a execução penal, a avó materna teria condições de zelar pelo bem-estar dos menores. O genitor afirmou que se encontrava em liberdade condicional, trabalhando na construção civil, com residência fixa, sendo, portanto, apto para a guarda dos filhos. Ambos os pais externaram afeto pelas crianças, bem como o interesse na manutenção do poder familiar, além de afirmarem que os crimes cometidos não se repetiriam, tendo sido lapsos momentâneos. Porém, o parecer da procuradoria, adotado no acórdão, se contrapõe aos pedidos, considerando o "absoluto desinteresse" dos pais "em assumir seus deveres maternais de forma minimamente responsável”. Esclarece que as crianças estavam em situação de risco e foram abrigadas porque se encontravam sob os cuidados da avó materna, "pessoa de idade avançada, doente e sem condições de dispensar os devidos cuidados aos infantes”. Prossegue:

Seus genitores (apelantes) sempre estiveram envolvidos com o tráfico de drogas e estavam presos. Registre-se que ambas as crianças nasceram na prisão, sendo que K. permaneceu por três anos na companhia da mãe na penitenciária. Após esse período, a apelante A. saiu da cadeia mas voltou a delinquir, sendo presa novamente. O apelante R., em liberdade condicional, manifestou desejo de cuidar dos filhos, sendo que o caso foi reavaliado pelo Serviço Auxiliar da Infância - SAI - o qual concluiu ser a destituição do poder familiar a solução adequada para o futuro das crianças. Extrai-se do relatório do SAI que “... R. relatou que quase não conviveu com os filhos, ou seja, logo após o nascimento de K. ele foi preso, voltou a vê-la quando ela já estava com mais de 3 anos e 6 meses. Recebeu o benefício de 
liberdade condicional, conviveu 6 meses com a criança e logo foi preso novamente. Com o filho Rb., não conviveu, a criança está com 2 anos e 5 meses, e há três meses visita-o no abrigo uma vez por semana. Desde que as crianças nasceram ele cumpriu pena pelos crimes que cometeu. R. teve chance para cuidar dos filhos em liberdade, mas logo voltou a traficar drogas... Há mais de 10 anos está envolvido com o tráfico... K. continua manifestando que não quer ficar com seus pais...”.

Esse triste exemplo de uma família completamente esfacelada, seja pelo tráfico, seja pelo círculo vicioso da reiteração criminosa, foi percebido em vários casos e nos faz refletir sobre diversas políticas públicas ausentes na garantia dos direitos dessas crianças (e de suas mães/pais). É premente a necessidade de implantação de uma rede de ações que garanta efetivamente a inclusão no mercado de trabalho formal, em programas de moradia, saúde e educação de qualidade para essas parcelas extremamente vulneráveis da sociedade. Sem sombra de dúvida, os muros (visíveis e invisíveis) da prisão vão muito além das grades do sistema penitenciário e a suposta (re)inserção social tanto das mães (e pais) quanto das crianças que vivenciaram o cotidiano do cárcere exige a adoção de medidas proativas por parte do Estado e da coletividade, que objetivem materialmente a construção de uma sociedade verdadeiramente justa e solidária.

A conquista desse objetivo fundamental pressupõe, no tocante ao tema pesquisado, um debate sobre a responsabilização das diferentes esferas estatais. Porém, a discussão no âmbito do Judiciário acerca da responsabilidade do Estado pôde ser observada em apenas um único caso: uma ação de indenização em face do estado do Paraná com pedido de alimentos provisórios formulado pelo filho de uma presa, a qual faleceu em estabelecimento prisional após piora do seu estado de saúde. A criança tinha pouco mais de um ano, era portadora do vírus HIV, necessitando de cuidados médicos especiais, e estava sob a guarda da avó materna, a qual não reunia condições financeiras para arcar com todas as despesas.

De acordo com o publicizado na decisão do TJPR (Agravo de Instrumento 340622 4), durante o trâmite do processo-crime, a mulher privada de liberdade tomou ciência de que estava grávida e era portadora do vírus HIV. Após o parto, foi indicada alta hospitalar e a mãe encaminhada à Delegacia de Polícia, que estava em condições totalmente insalubres. Sua advogada requereu a permanência em local adequado, e, após ampla discussão, permitiram que ela permanecesse em um quarto anexo à cozinha do minipresídio. Depois de alguns dias, o sargento responsável pelo cárcere demonstrou resistência em mantê-la em local separado e colocou-a junto com as demais presas. No mês seguinte, diante de uma rebelião ocorrida no presídio, as detentas foram transferidas para outra cadeia pública, onde o estado de saúde da presa agravou-se completamente em razão da tuberculose adquirida. Um ano depois, o gestor administrativo 
dessa cadeia encaminhou ao delegado-chefe relatório pormenorizado sobre a situação emergencial da detenta, alegando ainda que o fato gerava revoltas constantes na população carcerária, e só então foi determinada sua remoção para um instituto hospitalar, tardiamente, pois três dias depois ela faleceu, deixando desprotegido seu filho. E assim prossegue:

a pretensão formulada pelo autor não se refere ao fato de ter contraído a AIDS e sim a tuberculose, em decorrência da negligência dos agentes do Estado no resguardo de sua saúde, colocando-a em local separado, pois tinham conhecimento de que era portadora de doença que baixa a imunidade e do risco de ser contagiada pela doença que acarretou sua morte; o cerne da controvérsia refere-se ao fato de que, por ser a mãe do autor portadora dessa síndrome, a situação exigia maiores cuidados por parte do Estado, que tem o dever de zelar pela integridade física e moral dos detentos, conforme determina o art. $5^{\circ}$, XLIX, da CF; a falecida adquiriu tuberculose durante a sua permanência na cadeia pública, por ter tido contato com outra detenta que estava acometida da doença; [...] a responsabilidade do Estado é objetiva (art. 37, § 6 ${ }^{\circ}$, da CF) e, no caso, decorre do seu dever de zelar pela integridade física dos detentos; por fim, sustenta que a situação financeira do autor torna imprescindível a prestação de alimentos por parte do Estado como meio de subsistência e manutenção de sua saúde.

Nesse caso especificamente, convém pontuarmos os argumentos do governo do Paraná, que se insurgiu contra a concessão da pensão de um salário mínimo ao filho da presa, para que tenhamos dimensão das teses de escusa da responsabilidade estatal. Alegou, dentre outros argumentos, que: não havia prova inequívoca da culpa da administração na morte da presa, condenada por tráfico ilícito de entorpecentes e associação para o tráfico; não havia prova do nexo de causalidade entre a eventual ação omissiva do Estado e o resultado danoso; a documentação constante no processo revelava que a mãe contraiu AIDS - doença grave e quase sempre incurável - sem qualquer culpa do Estado e que sua morte foi resultante dessa doença, aliada à tuberculose e ao puerpério; não houve omissão, pois quando o estado de saúde da detenta se agravou ela foi conduzida ao hospital. O governo do Paraná acrescentou que "o fato de ela estar em cadeia pública não guarda qualquer relação com a responsabilidade do Estado, na medida em que ela é responsável pela própria segregação por cometer crimes”; e o indeferimento do pedido de prisão domiciliar representa juízo privativo do Poder Judiciário, que não serve para acarretar a responsabilidade civil estatal.

O TJPR, todavia, entendeu que o Estado era responsável pela morte da mãe presa, na medida em que não tomou as providências adequadas, no sentido de lhe 
garantir o direito à saúde; portanto, manteve a tutela para o pagamento da pensão ao filho. Sustentou, dentre outros argumentos, a tese de que o dano resultou da omissão específica, ou seja, "a inércia administrativa foi a causa direta e imediata para que não se impedisse o evento, logo, o Estado responde objetivamente".

Os processos criminais no Paraná também envolviam pedidos de concessão ou prorrogação de prisão domiciliar (treze), liberdade provisória (sete) e revogação da prisão preventiva (dois). Os dois pedidos de revogação de prisões preventivas foram aceitos. Tratavam de denúncias por tráfico de drogas, de acusadas primárias, mães de filhos em fase de amamentação, que não eram acusadas principais nos processos, não existindo motivos para a decretação da prisão preventiva (HC 282682-8; HC 709418-2).

Quanto aos pedidos de prisão domiciliar, onze foram negados e dois foram aceitos. Proporcionalmente, foram as decisões de liberdade provisória: cinco indeferidas e somente uma aceita (outra perdeu o objeto diante da absolvição da presa).

No TJSP, das 114 decisões encontradas na busca inicial, somente três atendiam aos critérios de inclusão da pesquisa, ressalvando-se que não foi possível a análise de alguns processos por se tratar de segredo de justiça. Seguindo a metodologia definida para todos os sites (pesquisa avançada com o uso do período de 01/01/2002 a 10/11/2012), especificamente no TJSP o resultado foi bastante escasso. Logo, foi necessário incluir também uma pesquisa básica, sem especificar o período, para complementar a planilha com um número maior de decisões, a fim de consolidar de forma mais estável o posicionamento daquele tribunal sobre o tema. Assim, mais sete acórdãos foram incluídos, todos julgados de 22/11/2012 a 25/03/2013, totalizando dez processos.

As decisões foram proferidas por órgãos colegiados do tribunal e apenas uma trata de matéria cível, qual seja, a regulamentação de visitas de filho menor. Neste caso (Agravo de Instrumento 9025883-78.2009.8.26.0000), o filho residia com o pai desde os quatro meses de idade em razão de sua mãe ter sido presa ainda gestante. Depois de cumprida a pena, a mãe passou a exercer o direito de visitas amigavelmente, contudo, após desentendimentos, foi ajuizada pelo genitor medida cautelar de busca e apreensão da criança, com rompimento do contato com a mãe desde então. Conforme exposto pelo Relator Desembargador Luiz Antonio de Godoy, “o direito de visitas pertence não apenas a quem não detém a guarda nem a exerce, mas, igualmente, à prole. Assim, há necessidade de encontrar soluções que resguardem seus interesses e bem-estar”. Por isso, foi garantido à mãe o direito de conviver com o filho, determinando-se visitas semanais em local público.

Em oito dos nove processos criminais julgados pelo TJSP, foi requerida prisão domiciliar; todos, de modo geral, com o fundamento de a mãe ter filho recém-nascido em fase de amamentação. Somente em uma situação foi deferida, para permitir o direito da mulher permanecer com o filho. Todos os demais foram negados, ou julgados prejudicados. Os desembargadores utilizam o argumento de "vedação expressa 
da concessão do benefício da liberdade provisória em crimes de tráfico de drogas” e a inviabilidade da concessão de prisão domiciliar, bem como a "ausência de prova idônea” de que o filho depende de fato da mãe. O perfil das mães é o mesmo revelado nos outros tribunais: grande maioria primária, com residência fixa e denunciada por tráfico de entorpecentes.

Houve, ainda, um pedido de liberdade provisória, também negado, para uma presa denunciada por tentativa de homicídio qualificado, segundo o órgão julgador, diante da gravidade da conduta (HC 0268333-06.2012.8.26.0000).

Por fim, debruçamo-nos sobre as decisões do TJMT. Apesar da dificuldade inicial de obtenção dos dados em razão das limitações do site de busca - como não disponibilizar o link das decisões, nem um tutorial de busca ou auxílio a pesquisadores -, esse tribunal foi o que apresentou maior quantidade de decisões atinentes ao objeto do nosso estudo. Foram 38 encontradas, sendo apenas uma no âmbito civil (Agravo de Instrumento 0071987-07.2009.8.11.0000), a qual se referia a um pedido de revogação da decisão de suspensão do poder familiar. O pedido liminar foi aceito, para que a criança retornasse ao convívio com sua genitora, reclusa na Cadeia Pública, em prol do melhor interesse da criança, de modo a garantir-lhe o aleitamento materno, com base no artigo 83, § $2^{\circ}$, da LEP (Lei n. 7.210/84).

No TJMT, percebeu-se um forte debate jurisprudencial acerca da situação das mães com filhos no cárcere, sendo o único estado no qual se identificou uma ação coletiva do Ministério Público, requerendo prisão domiciliar para 47 presas, ou, alternativamente, que as crianças fossem encaminhadas aos familiares e/ou na falta destes para um abrigo para crianças, com deslocamento diário da mãe para o local para a amamentação dos filhos (HC com efeitos coletivos 0074015-74.2011.8.11.0000, julgado em 18/11/2011).

As presas ficam com os filhos menores de 5 anos em celas insalubres, o que configuraria ato ilegal perpetrado pelo secretário de Estado de Cidadania e pelo juiz da $2^{a}$ Vara Criminal da capital, de acordo com o relato do Ministério Público local. Ressalta que as crianças não recebem alimentação adequada, não há pediatra no local nem sequer medicamentos infantis, ficam aguardando a visita do médico do presídio sem expediente contínuo, dentre outras várias questões. Informa, ainda, que foi proposta Ação Civil Pública n. 1425-07.2011.811.0063, perante a la Vara da Infância e do Adolescente da capital, buscando garantir o direito líquido e certo da amamentação dos filhos de mães presidiárias, a fim de que seja restabelecido o direito à dignidade da pessoa humana, não inviabilizando a utilização concomitante do habeas corpus coletivo. Acrescenta:

(As crianças) estão sendo tratadas iguais às suas mães, como presas, pois vivem em celas, em local insalubre, sem janelas de proteção do frio, chuva, mosquitos, além de dormirem ao lado dos “BOIS" - sanitários dos 
presídios. Sustenta ainda que por não ter proteção acústica, as crianças ficam suscetíveis aos gritos, ferrolhos das portas abrindo e fechando, o que as deixam sempre em sobressaltos e estado de alerta. (Grifo nosso.)

O habeas corpus foi distribuído para a Turma de Câmaras Criminais Reunidas, porque um secretário de Estado estava sendo apontado como autoridade coatora, configurando o chamado foro privilegiado. Inicialmente, o Desembargador Relator proferiu voto no sentido de considerar o TJMT incompetente em relação a três presas oriundas da justiça federal; prejudicado o pedido para 26 presas que já haviam conseguido a prisão domiciliar; e iria deferir a prisão domiciliar para as demais. Contudo, outro magistrado (vogal) discordou do encaminhamento anterior, entendendo que o secretário de Estado não era autoridade coatora, pois não poderia decidir acerca de pedidos de prisão domiciliar. Os demais desembargadores votantes acompanharam o entendimento do vogal/revisor, e o relator reviu seu voto, seguindo os demais. Desse modo, foi excluída a autoridade estadual, findo o foro privilegiado e remetido o processo a uma Câmara Criminal para apreciar o pedido. A impetração desse habeas corpus não implicou um resultado processual satisfatório de imediato, pois não foi proferida uma decisão de mérito favorável naquela ocasião. Entretanto, na prática, foi uma medida com certo grau de eficácia, pois estimulou a decretação das prisões domiciliares das mães pelos juízes de primeira instância e o debate acerca das condições de permanência com seus filhos no cárcere.

As ações criminais individuais restantes, como nos demais tribunais analisados, discutem a concessão de prisão domiciliar (quinze, sendo nove negadas), liberdade provisória (onze, com dez indeferidas), revogação de prisão preventiva ou relaxamento de prisão (sete, sendo três deferidas e uma que perdeu objeto diante da prolação da sentença e obtenção da prisão domiciliar). Neste último caso, o juiz de primeira instância informou que a presa foi condenada a 5 anos e 6 meses de reclusão e ao pagamento de 500 dias multa pelo delito de tráfico de drogas e, embora não fosse caso de substituição de pena privativa de liberdade por restritivas de direito, concedia prisão domiciliar à sentenciada, "em razão de encontrar-se segregada com filho menor" (HC 0049776-69.2012.8.11.0000).

Destaca-se, exemplificativamente, um pedido de liberdade provisória indeferido a uma presa que respondia pelos crimes de tráfico de drogas (art. 33 da Lei n. 11.343/06) e corrupção de menor (art. 244-B do ECA). Apesar de o tribunal considerar presentes os requisitos autorizadores da prisão cautelar previstos no artigo 312 do Código de Processo Penal, concedeu a prisão domiciliar, em caráter excepcional, para acolhimento das necessidades da filha da ré. Reconheceu a peculiaridade de se tratar de criança de 2 meses nascida prematuramente e enferma, a necessitar, induvidosamente, da assistência e cuidado materno. "Mesmo diante da necessidade da garantia da ordem 
pública, ante a gravidade concreta das infrações supostamente praticadas pela paciente”, a proteção integral ao direito indisponível e irrenunciável da criança à alimentação e à saúde foi permitida em sede cautelar (HC 0008395-18.2011.8.11.0000).

Nessa situação fática de ponderação de interesses, prevaleceu a garantia dos direitos da criança de ser acompanhada da mãe em face do discurso de repressão jurídica e social. Porém, essa não foi a tônica utilizada em outros pedidos de liberdade provisória, como se constata no HC 0028986-64.2012.8.11.0000. Nesse processo por tráfico de drogas, receptação e porte ilegal de arma de fogo, a presa pleiteava a liberdade provisória ou, subsidiariamente, a prisão domiciliar para que pudesse cuidar do filho de 11 meses de idade, dentre outros motivos. Todavia, o tribunal considerou que, diante dos "fortes indícios de ocorrência dos crimes", deveria permanecer a prisão preventiva.

Outro recurso para reforma da sentença com redução de pena foi julgado improcedente; bem como uma solicitação de substituição da pena privativa de liberdade por restritiva de direitos, também negada, garantindo-se à presa apenas a mudança do regime prisional para semiaberto. Por fim, foi identificado, ainda, o pedido do filho de uma presa para visitá-la na prisão. A criança tinha 10 anos, e o juiz criminal havia negado sua entrada no presídio pelo argumento de que o estabelecimento prisional não ofereceria condições de segurança e higiene adequadas a sua proteção integral. O tribunal reformou essa decisão e privilegiou o direito da presa de conviver com sua família, entendendo que o afastamento do convívio com a genitora se mostra mais prejudicial ao filho do que sua exposição à realidade do ambiente prisional, sendo dever do Estado oferecer as condições de segurança necessárias (Apelação Criminal 0002940-34.2011.8.11.0045).

\section{CONSIDERAÇÕES FINAIS}

De modo geral, nos documentos analisados, observamos certa constância de assuntos e argumentos utilizados diante do incipiente debate a respeito do tema durante o período pesquisado. O baixo número de decisões diretamente correlacionadas ao objeto deste estudo, consideradas proporcionalmente em relação ao número de anos pesquisados, evidencia que o assunto não foi debatido com frequência nos Tribunais Superiores e em alguns Tribunais Locais no decorrer dos dez anos analisados. O resultado sugere a existência de dificuldades de acesso à justiça por parte das mulheres presas e seus filhos, bem como a invisibilidade social da questão.

Dentre os pedidos analisados pelo Judiciário, destaca-se a prisão domiciliar, seguida das solicitações de liberdade provisória. Alguns pontos de tensão são observados ao serem correlacionadas medidas de proteção e garantias da criança com direitos da mulher presa referentes à execução penal. Assim, por exemplo, as características do filho ser nascituro, menor de 7 anos ou portador de deficiência são utilizadas como 
argumentos e, em alguns casos, justificam a concessão do pedido de prisão domiciliar, a partir de uma interpretação equitativa, que vai ao encontro dos critérios legalmente previstos.

A prevalência das acusações por tráfico de entorpecentes também é uma variável importante a ser considerada. A aplicação da Lei de Drogas (Lei n. 11.343/06) combinada com a Lei de Crimes Hediondos (Lei n. 8.072/90) implica uma enorme limitação à concessão de benefícios processuais e correlacionados à execução penal. Por exemplo, inviabiliza a concessão de fiança, bem como aumenta o prazo para a progressão do regime prisional e para o livramento condicional.

Com base nos resultados da pesquisa desenvolvida, foi possível perceber que, majoritariamente, a jurisprudência dos tribunais caminhou no sentido de reafirmar o discurso da segurança e manutenção da ordem em face do direito indisponível e irrenunciável da criança à alimentação, à saúde e à convivência com sua mãe. A fundamentação com base nas restrições normativas gerais correlacionadas ao caráter de hediondez associado ao delito prevalece como maior valor ponderado.

Dessa forma, acentua-se o ciclo da violência institucional, pois, quando um pedido de liberdade provisória ou prisão domiciliar para a mãe permanecer com o filho que necessita de seus cuidados é negado em função da natureza da condenação pelo crime de tráfico, apenas se retroalimentam as consequências nefastas do encarceramento para a família. Com relação à questão das drogas, Wacquant observa que o argumento habitualmente invocado de que a inflação carcerária corresponde a uma redução automática da criminalidade ao "neutralizar” os condenados atrás das grades, que assim não oferecem mais perigo, revela-se ilusório, porque, "quando aplicado à delinquência de baixa periculosidade, o encarceramento desmesurado equivale a 'recrutar' novos delinquentes por efeito de substituição" (WACQUANT, 2004, p. 222). Uma vendedora de pequena quantidade de droga detida é imediatamente substituída por outra, contanto que haja uma demanda da mercadoria e expectativa de lucro. E essa substituta estará mais disposta à violência para se firmar e assegurar seu negócio, redundando em mais criminalidade. Ademais:

a prisão tem a característica de uma bomba social que aspira-e-expele: ela devolve à sociedade indivíduos capazes de cometer ainda mais delitos e crimes em virtude do corte sociobiográfico que a reclusão exerce; da carência de programas de "reinserção" durante e após o encarceramento; e da série de restrições, incapacidades e outros prejuízos decorrentes de uma passagem pela polícia. (WACQUANT, 2004, p. 222).

Por estar privada de liberdade, as condições de cumprimento da pena da mulher repercutem em seus filhos, notadamente naqueles de parca idade que permanecem no cárcere, implicando grave violação a direito fundamental, por não serem oferecidas 
condições de adequada assistência. Em geral, não é observado o princípio constitucional da intranscendência da pena, segundo o qual nenhuma pena passará da pessoa do condenado, nos exatos termos do artigo $5^{\circ}$, inciso XLV, da Constituição Federal brasileira.

Com relação aos poucos processos cíveis encontrados, imperou a lógica da destituição do poder familiar diante da ausência de políticas públicas focalizadas para essa parcela da sociedade. É praticamente inexistente o debate acerca da responsabilização estatal no desenvolvimento físico e emocional das crianças que se encontram recolhidas com suas mães nas prisões e de outros filhos que permanecem privados de sua genitora.

A análise comparativa entre os tribunais evidencia, ainda, que em alguns estados, como Mato Grosso e Rio Grande do Sul, o debate acerca dos direitos das presas e seus filhos vem se intensificando, conquanto ainda seja insuficiente. Entretanto, nos demais estados analisados e nos Tribunais Superiores, a questão da maternidade no cárcere raramente foi abordada, o que contrasta com a ampla ocorrência de violações de direitos humanos vivenciadas pelas mulheres e seus filhos no cárcere. Como inicialmente destacado, a questão abordada envolve um conjunto de direitos individuais e sociais reconhecidos constitucionalmente, também contemplados na legislação ordinária específica e em tratados internacionais, os quais deveriam servir como fundamento e motivação para um maior número de postulações ao Judiciário.

Fechamos este nosso diagnóstico geral a respeito de como foi tratado o assunto pelo Judiciário com uma inquietação: será que a questão dessas mulheres mantidas no cárcere com seus filhos se reduziria, de modo geral, a pedidos de prisão domiciliar, liberdade provisória ou suspensão do poder familiar? Temos, ao menos, uma certeza: estudos e reflexões a respeito são necessários e bem-vindos para que possamos construir uma atuação judicial efetivamente justa e democrática, conforme a Constituição brasileira e as recomendações internacionais da Conferência do Cairo no tocante aos direitos da família, de reprodução e saúde reprodutiva, saúde e pesquisa (ONU, 1994), bem como as Regras de Bangkok sobre o encarceramento feminino (ONU, 2010).

Tornar o tema visível e fomentar seu debate contribuem não apenas para um tratamento equitativo e justo da garantia dos direitos de mulheres e crianças à saúde, maternidade e convivência familiar, mas também permitem repensarmos que modelo social desejamos e quais interesses deverão ser privilegiados na construção de políticas públicas. Por enquanto, medidas de encarceramento têm predominado na jurisprudência dos tribunais brasileiros em detrimento à adoção da perspectiva equitativa exigida pelos direitos humanos. Tal fato no cenário brasileiro representa um descompasso grave de ausência de efetividade do estatuto legal.

Após o término da pesquisa e a submissão deste artigo, algumas decisões judiciais demonstram uma preocupação crescente com o tema, percebida também no 
campo das políticas públicas, com a publicação de normas e recomendações federais que marcaram avanços significativos. ${ }^{4}$ Em particular, no âmbito jurisprudencial, foi prolatada uma decisão emblemática pela presidência do STF. Conquanto esteja fora do recorte temporal pesquisado, convém comentá-la, inclusive no intuito de fomentar futuras análises empíricas. Trata-se de um habeas corpus impetrado pela Defensoria Pública de São Paulo em favor de uma mulher que se encontrava presa provisoriamente, portadora de cardiopatia grave e em estágio avançado de gestação. A decisão, proferida pelo Ministro Ricardo Lewandowski no período de recesso, foi publicada no dia 2 de fevereiro de 2015 e concedeu de ofício a substituição imediata da prisão preventiva por prisão domiciliar, com fundamento no artigo 318, inciso IV, do CPP. Atento às condições pessoais da acusada e do nascituro, "a quem certamente não se pode estender os efeitos de eventual e futura pena” (art. 5 XLV, CF), o STF adota explicitamente as Regras Mínimas para Mulheres Presas (Regras de Bangkok), destacando a necessidade de se desenvolver opções de medidas e alternativas à prisão preventiva e à pena especificamente voltadas às mulheres infratoras, dentro do sistema jurídico do Estado membro, considerando o histórico de vitimização de diversas mulheres e suas responsabilidades maternas. (HC 126107/DF.)

Foram consideradas, ainda, a situação de superlotação da penitenciária na qual encontrava-se a gestante, bem como o direito à prioridade no âmbito dos serviços públicos, insculpido na Lei n. 10.048/00.

Encerramos, então, este artigo com ares de esperança, almejando que o retrato jurisprudencial brasileiro desenhado entre os anos de 2002 e 2012 seja modificado, no sentido de garantir a efetividade dos direitos humanos de mães privadas de liberdade e seus filhos.

NOTAS

* Agradecemos a Maria do Carmo Leal, Alexandra Sánchez e Vilma Diuana de Castro, pelas preciosas sugestões no desenvolvimento do trabalho. Ao Ministério da Saúde, Departamento de Assistência e Promoção à Saúde (DAPS) e à Escola Nacional de Saúde Pública (ENSP/Fiocruz) pelo apoio à pesquisa. Igualmente, aos avaliadores anônimos pelas valiosas críticas e sugestões.

1 O direito à amamentação pôde ser observado no trabalho de Pedro Oto Quadros e Rosângela P. Santa Rita, os quais defendem que "o avanço das ciências nas últimas três décadas mostra que o atendimento de crianças até os 
três anos de idade com a qualidade técnica requerida é um bom caminho para uma sociedade mais equilibrada e solidária, mais justa, menos violenta” (2008, p. 2). Com base nos princípios da proteção integral, da prioridade absoluta da criança e do interesse superior da criança, propõem a adoção de medidas efetivas para a garantia da amamentação às crianças com até dois anos de idade.

2 Refere-se às alterações promovidas pela Lei n. 12.403/11, cunhadas como reforma das medidas cautelares.

3 O princípio da dignidade da pessoa humana foi empregado como categoria analítica fundamental no trabalho de Rosângela Peixoto Santa Rita (2006), associado a referenciais normativos utilizados nas ações institucionais na prisão. A autora observa que não há uma correspondência entre o expresso nos instrumentos legais e a realidade vivenciada pela mulher-mãe presa. Destarte, propõe a implementação de políticas públicas específicas, no sentido de minimizar o poder discricionário das gestões penitenciárias.

4 Acerca do tema, foram instituídas a Política Nacional de Atenção Integral à Saúde das Pessoas Privadas de Liberdade no Sistema Prisional (PNAISP) no âmbito do Sistema Único de Saúde (SUS), pela Portaria Interministerial n. 01, de 02/01/2014; bem como a Política Nacional de Atenção às Mulheres em Situação de Privação de Liberdade e Egressas do Sistema Prisional, nos termos da Portaria Interministerial n. 210, de 16/01/2014.

\section{REFERÊNCIAS BIBLIOGRÁFICAS}

ARMELIN, Bruna Dal Fiume. Filhos do cárcere: estudo sobre as mães que vivem com seus filhos em regime fechado. Revista da Graduação, v. 3, n. 2, 2010. Disponível em: <http://revistaseletronicas.pucrs.br/ojs/ index.php/graduacao/article/viewFile/7901/5586>. Acesso em: 20 dez. 2012.

BRASIL. Portaria Interministerial n. 210, de 16 de janeiro de 2014. Institui a Política Nacional de Atenção às Mulheres em Situação de Privação de Liberdade e Egressas do Sistema Prisional, e dá outras providências. Diário Oficial, Brasília, DF, 2014.

. Portaria Interministerial n. 01, de 02 de janeiro de 2014. Política Nacional de Atenção Integral à Saúde das Pessoas Privadas de Liberdade no Sistema Prisional (PNAISP) no âmbito do Sistema Único de Saúde (SUS). Diário Oficial, Brasília, DF, 2014.

Constituição Federal. Brasília: Congresso Nacional, 1988.

. Ministério da Saúde. Direitos sexuais e direitos reprodutivos: uma prioridade do governo. Brasília, 2005.

(Série A. Normas e Manuais Técnicos - Série Direitos Sexuais e Direitos Reprodutivos, Caderno no 1). DEPARTAMENTO PENITENCIÁRIO NACIONAL (DEPEN). Ministério da Justiça. Mulheres presas - Dados gerais. Brasília, 2011. Disponível em: <http://portal.mj.gov.br/main.asp?View=\%7B71FD341F-0531-4BAB$\mathrm{A} 56772586745 \mathrm{CB} 18 \% 7 \mathrm{D} \&$ Team $=\&$ params $=\mathrm{itemID}=\% 7 \mathrm{~B} 0892 \mathrm{E} 0 \mathrm{~A} 1-29 \mathrm{D} 4-4 \mathrm{E} 56-\mathrm{AF} 95-6 \mathrm{~B} 4 \mathrm{~B} 6 \mathrm{EC} 869 \mathrm{~A} 2 \% 7 \mathrm{D}$; \&UIPartUID=\%7B2868BA3C-1C72-4347-BE11-A26F70F4CB26\%7D>. Acesso em: 12 out. 2013.

LEAL, Maria do Carmo et al. Relatório do projeto de pesquisa Saúde Materno-Infantil nas Prisões do Brasil. Rio de Janeiro: Escola Nacional de Saúde Pública Sérgio Arouca/Fundação Oswaldo Cruz, 2014.

LEMGRUBER, Julita. Cemitério dos vivos: análise sociológica de uma prisão de mulheres. Rio de Janeiro: Forense, 1999.

Regras das Nações Unidas para o tratamento de mulheres presas e medidas não privativas de liberdade para mulheres infratoras. Bangkok, 2010. Disponível em: <http://carceraria.org.br/wp-content/uploads/2012/09/Tradu\%C3 \%A7\%C3\%A3o-n\%C3\%A3o-oficial-das-Regras-de-Bangkok-em-11-04-2012.pdf>. Acesso em: 12 out. 2013.

ORGANIZAÇÃO DAS NAÇÕES UNIDAS (ONU). Relatório da Conferência Internacional sobre População e Desenvolvimento. Cairo, 1994. Disponível em: <http://www.unfpa.org.br/Arquivos/relatorio-cairo.pdf>. Acesso em: 12 out. 2013.

QUADROS, Pedro Oto; SANTA RITA, Rosângela Peixoto. Amamentação: direito da mãe ou da criança? Um olhar sobre as práticas do encarceramento feminino. Tese relativa ao Bloco Temático 3: Direito à vida, à saúde e a condições dignas de sobrevivência, XXII Congresso da Associação Brasileira de Magistrados e Promotores de Justiça da Infância e da Juventude. Florianópolis, 2008.

SANTA RITA, Rosângela Peixoto. Mães e crianças atrás das grades: em questão o princípio da dignidade da pessoa humana. 2006. Dissertação (Mestrado em Política Social) -Universidade de Brasília, Brasília, 2006. 
SANTOS, Raquel Costa de Souza. Maternidade no cárcere: reflexões sobre o sistema penitenciário feminino. 2011. Dissertação (Mestrado) - Universidade Federal Fluminense, Niterói, 2011.

STELLA, Claudia. Filhos de mulheres presas: o papel materno na socialização dos indivíduos. Estudos e Pesquisas em Psicologia, Rio de Janeiro, ano 9, n. 2, p. 292-306, 2009. Disponível em: <http://www.revispsi.uerj.br/ v9n2/artigos/pdf/v9n2a03.pdf>. Acesso em: 3 out. 2015.

VALENTE, Rodolfo de Almeida; CERNEKA, Heidi Ann; BALERA, Fernanda Penteado. Mães encarceradas: a delicada relação entre os direitos da criança e a lei. São Paulo, 2011. Disponível em: <http://www.conjur.com.br/ 2011 set-18/maternidade-prisão-delicada-relacão-entre-direitos-crianca-lei>. Acesso em: 20 dez. 2012.

VENTURA, Miriam; SIMAS, Luciana; LAROUZÉ, Bernard. Maternidade atrás das grades: em busca da cidadania e da saúde. Um estudo sobre a legislação brasileira. Cadernos de Saúde Pública, v. 31, n. 3, p. 607 619, mar. 2015.

. Direitos reprodutivos no Brasil. 3. ed. Brasília: UNFPA, 2009.

WACQUANT, Loïc. A aberração carcerária à moda francesa. Dados, v. 47, n. 2, p. 215-232, 2004.

. Punir os pobres: a nova geração da miséria nos Estados Unidos. 2. ed. Rio de Janeiro: Revan, 2003.

Luciana Simas

Rio de Janeiro - RJ - Brasil

luciana.simaslaig.com.br

de Janeiro - RJ - Brasil

miriam.venturadiesc.ufrj.br

Rio de Janeiro - RJ - Brasil

michellyribeirobaptistalagmail.com

Rio de Janeiro - RJ - Brasil bernard.larouzelainserm. fr

\section{Miriam Ventura}

Advogada.

Professora AdJunta do Instituto de Estudos em SAÚde Coletiva (IESC/UFRJ) e dos Programas de Pós-Graduação em Bioética, Ética Aplicada e Saúde Coletiva (INTERINSTITUCIONAL ENTRE UFRJ, FIOCRUZ, UERJ E UFF) e Programa de Saúde Coletiva (IESC/UFRJ).

Doutora em Saúde Pública.

\section{Michelly Ribeiro Baptista}

Advogada.

ASSISTENTE DE PESQUISA DO PROJETO NASCER NO BRASIL (ENSP/FIOCRUZ).

\section{Bernard Larouzé}

Médico, Diretor de Pesquisa Emérito, Sorbonne UnIVERSITÉ, UPMC UnIV. PARIS 06, INSERM, IPLESP UMRS 1136, EquiPE dE RECHERCHE EN EPIDÉMIOLOGIE Sociale, F75012, Paris, frança.

Pesquisador visitante da Escola Nacional de Saúde Pública/FIocruz. 
